University of Nebraska - Lincoln

DigitalCommons@University of Nebraska - Lincoln

Faculty Publications, Department of Psychology

Psychology, Department of

April 1999

\title{
Adolescent Victims and Intergenerational Issues in Sexual Abuse
}

Debra B. Hecht

University of Nebraska-Lincoln

David J. Hansen

Univertsity of Nebraska-Lincoln, dhansen1@unl.edu

Follow this and additional works at: https://digitalcommons.unl.edu/psychfacpub

Part of the Psychiatry and Psychology Commons

Hecht, Debra B. and Hansen, David J., "Adolescent Victims and Intergenerational Issues in Sexual Abuse" (1999). Faculty Publications, Department of Psychology. 220.

https://digitalcommons.unl.edu/psychfacpub/220

This Article is brought to you for free and open access by the Psychology, Department of at DigitalCommons@University of Nebraska - Lincoln. It has been accepted for inclusion in Faculty Publications, Department of Psychology by an authorized administrator of DigitalCommons@University of Nebraska - Lincoln. 


\title{
Adolescent Victims and Intergenerational Issues in Sexual Abuse
}

\author{
Debra B. Hecht and David J. Hansen \\ Department of Psychology, University of Nebraska-Lincoln
}

\section{Introduction}

The transitional period of adolescence is characterized by a number of changes and challenges that occur both within and outside the individual. Many developmental events occur during adolescence that have a significant impact on an adolescent's functioning, including a variety of physical, cognitive, emotional, behavioral, and social changes. In addition, adolescents may experience a variety of other important events, such as peer group changes, school moves, changes in family structure or functioning, and alterations in societal and community expectations (Hansen, Giacoletti, \& Nangle, 1995; Peterson \& Hamburg, 1986). Unfortunately, many adolescents are further challenged by being a victim of sexual abuse.

The widespread prevalence of sexual abuse and the numerous problems and consequences associated with it have been increasingly recognized in recent decades (e.g., Browne \& Finkelhor, 1986; Faller, 1993; V. V. Wolfe \& Wolfe, 1988). In addition, much has been learned about the treatment of sexually abused children and adolescents during that time (e.g., Hansen, Hecht, \& Futa, 1998; O’Donohue \& Elliot, 1992). Given that victims of sexual abuse are at risk to develop sexualized behaviors, and that adolescents, for a variety of reasons (e.g., puberty, peer influences) are likely to begin engaging in sexual acts, this population needs special attention to help prevent the intergenerational transmission of abuse.

This chapter addresses sexual abuse of adolescent victims and intergenerational issues in sexual abuse. The problem of sexual abuse is described, including historical background and epidemiological information. The potential impact and correlates of sexual abuse are discussed, including characteristics of adolescent victims and their families. The assessment and treatment of sexually abused adolescents is described, with attention to issues of prognosis and clinical management. 


\section{Description of the Problem}

Child sexual abuse is a growing problem in today's society, and surprisingly, no definitional criteria have been universally accepted (Hansen et al., 1998; V. V. Wolfe \& Wolfe, 1988). Most definitions of sexual abuse consist of two main components: the specific sexual behaviors involved and the ages of the victim and the perpetrator (Browne \& Finkelhor, 1986; V. V. Wolfe \& Wolfe, 1988). Definitions usually emphasize that the sexual activity has occurred between children (e.g., under the age of 16) and older persons (generally defined as more than 5 years older than the child). This often creates some ambiguity when deciding whether sexual abuse has occurred with an adolescent, either as a victim or a perpetrator, because often the age difference is not as great as 5 years, but nonconsensual sex has occurred.

Sexual abuse tends to refer to abroad range of behaviors from noncontact to contact offenses. Noncontact activities include behaviors such as genital exposure, voyeurism, and pornography. Contact offenses refer to genital manipulation, digital or object penetration, penile penetration, and oral sex. In addition to the age and sexual behavior components, the relationship between the child and perpetrator is usually considered in the definition of sexual abuse. If the perpetrator is a family member, including distant relations, in-laws, and step-relatives, the abuse is considered intrafamilial sexual abuse or incest. If the perpetrator is an individual not related by marriage or blood, the abuse is considered extrafamilial. Most cases of abuse involve someone known to the family, however, whether or not an official family member (V. V. Wolfe \& Wolfe, 1988).

Lourie (1977) outlined a typology describing the onset of adolescent maltreatment. Type I refers to abuse that began in childhood and has continued into adolescence. Type II describes those cases in which the nature and amount of abuse increases in severity during the adolescent years, and is seen to be a result of the parents' inability or unwillingness to accept the adolescent's attempts at separation and individuation (Lourie, 1977; Williamson, Borduin, \& Howe, 1991). Type III abuse includes those instances when the abuse begins in adolescence, and again it is hypothesized that issues surrounding autonomy are a major contributing factor.

The effects and incidence of adolescent abuse may be overlooked for various reasons (Blythe, Hodges, \& Guterman, 1990; Lourie, 1977). Adolescent victims often are not brought to the attention of the authorities. Abuse in adolescence is thought to be harder to identify; there often is confusion between some of the telltale acting-out behaviors that are present in child victims and the normal developmental changes that are present in many adolescents (Blythe et al., 1990). This may be especially true with respect to sexual behaviors. It can be quite difficult at times to draw the line between normal experimentation and deviant behaviors. More details about the incidence and effects of abuse are described in later sections.

\section{Historical Background}

Adolescence covers the period typically beginning at puberty and extending to a socially defined period of "adulthood" which is not marked by any physical change. The end of adolescence tends to be defined more by legal statutes (e.g., voting and military age, 
ability to get married without parental consent or purchase alcohol). Although adolescents are now considered a distinct category of people in our society, this was not always true. Throughout much of history, adolescents were considered to be adults; with puberty came the rights and responsibilities of adulthood (Gonsiorek, 1994b). In our society, the concept of adolescence was largely initiated during the social and political changes of the industrial revolution, with larger cities, immigration of many youth, more property subject to delinquency, and changes in social policies and laws (e.g., compulsory education, child labor laws, special legal procedures for juveniles) (Gonsiorek, 1994b). With the concept of adolescence came changes in societal expectations regarding education, work, sexual activity, and marriage. Now with so many young people attending college, there appears to be a trend to prolong adolescence past the age of majority (Gonsiorek, 1994a).

Children and adolescents throughout much of history often have been treated with cruelty and received little protection from such treatment. Unfortunately, widespread societal concern over any form of child abuse as a significant problem dates back only to the 1950s and 1960s. Some of the original professional and public attention was focused more on the impact of physical abuse, following the description of the "battered child syndrome" (Kempe, Silverman, Steele, Droegenmueller, \& Silver, 1962). In recent decades, protection efforts for sexually abused children and adolescents have steadily increased, perhaps because of frequent and intense attention from diverse sectors of society-the media, the general public, the professional community, and legislators. The study of sexual abuse is also a relatively recent development, with a surge of attention in the 1970 s as victims came forward and talked about their experiences.

Historically, the involvement of adolescents in committing sexual offenses also received little attention and youth involved in committing sexual assaults were not held responsible for their acts. They were explained as "experimentation, " "adolescent adjustment reactions," or as a symptom of a greater emotional disturbance (National Adolescent Perpetrator Network [NAPN], 1993). Cases that were brought to court usually were not prosecuted, or the charges were reduced to a nonsexual offense before being filed (NAPN, 1993). It was not until the late 1970s to early 1980s that the issue of adolescent perpetrators was seriously addressed and interventions were considered and developed (NAPN, 1993). This was partly due to the discovery that adult perpetrators report beginning their offending behaviors while in their teens (Groth, Longo, \& McFadin, 1982). The increased attention to adolescent perpetrators logically followed the increased attention to victims, especially when some studies show that more than $50 \%$ of male victims were molested by an adolescent (Rogers \& Terry, 1984; Showers, Farber, Joseph, Oshino, \& Johnson, 1983).

\section{Epidemiology}

The National Center on Child Abuse and Neglect (NCCAN, 1996) recently reported the results of the Third National Incidence Study of Child Abuse and Neglect (NIS3). The NIS-3 is the most comprehensive study of the incidence of child abuse and neglect in the United States. The data were collected in 1993 from a nationally representative sample of more than 5, 600 professionals from 842 agencies in 42 counties. The NIS3 used two types of definitions of abuse and neglect. Children were considered maltreated under the harm standard only if they had already experienced harm (i.e., physical, 
emotional, or behavioral injury) from maltreatment. Children were considered maltreated under the more inclusive endangerment standard if they experienced maltreatment that put them at risk of harm or if they had already experienced harm. The endangerment standard enlarges the set of those to be considered perpetrators of sexual abuse by permitting children to count in the estimates if they are abused by teenage (i.e., nonadult) caretakers. Overall, there were substantial increases in the incidence of abuse and neglect since the earlier National Incidence Studies (NCCAN, 1996).

Based on the harm standard, it was estimated that 3.2 children per 1,000 (for a total of 217,700 nationwide) were known to be sexually abused in the United States. This is a significant increase over estimates from the earlier NIS Studies (NIS-2 was 1.9 per 1,000; NIS-1 was .7 per 1,000). Based on the endangerment standard, it was estimated that 4.5 children per 1,000 (for a total of 300,200 nationwide) were sexually abused. This is also a significant increase over the 1986 NIS-2 estimates of 2.1 per 1,000. (Endangerment definitions were not used in NIS-1.)

A variety of possible demographic correlates of maltreatment were examined in the NIS-3. The rates of sexual abuse (based on the harm standard) for males was 1.6 per 1,000 while the rate for females was over three times higher at 4.9 per 1,000. The rates according to the endangerment standard were 2.3 per 1,000 for males and 6.8 per 1,000 for females. Children from birth to 2 years were least likely to be sexually abused, and the rates of abuse were relatively constant across the ages from 3 years on. There were no significant race differences in the incidence of maltreatment or maltreatment-related injuries.

Rates of sexual abuse (harm standard) by family income were 7.0 per 1,000 for incomes less than $\$ 15,000$ per year, 2.8 per 1,000 for incomes between $\$ 15,000$ and $\$ 29,000$, and .4 per 1,000 for incomes of $\$ 30,000$ and greater. The rates according to the endangerment standard for these income groups were 9.2., 4.2, and 0.5 per 1,000, respectively. No differences in rates of sexual abuse were found for families of different sizes (i.e., number of children) or structure (i.e., single or two-parent family). No differences were found for metropolitan status of the community (i.e., very large urban, moderate urban, suburban, and rural).

Of the children who were sexually abused, $34 \%$ were reported to have serious or even fatal injury, $12 \%$ were reported to have moderate injury, and the remainder were determined to have inferred injury (i.e., it was assumed that some emotional, physical, or behavioral consequences of various levels of severity would have occurred). Across forms of abuse, males were $24 \%$ more likely than females to suffer serious injury. Children from the lowest income families (less than $\$ 15,000)$ were over 22 times more likely to be seriously injured from maltreatment than children from the higher income families.

These incidence figures probably underestimate the extent of the problem because these are only cases known to relevant agencies. Because of changes in child abuse definitions and the identification and handling of cases, estimates of the number of children abused in the United States have increased greatly over the past several years. It is unclear whether the figures reflect an actual increase in incidence or an increase in reporting due to growing public awareness, or both. Sexual abuse of adolescents is believed to be more underreported than sexual abuse of children because the public does not perceive adolescents at as much risk and adolescents are seen as better able to fight back or remove themselves from the situation. 
Incidence figures reflect only cases that occurred and were identified during the year investigated (e.g., 1993 for the NIS-3). Estimates of the prevalence of sexual abuse, which addresses the total number of persons sexually abused during childhood, are much larger and rather speculative. Professionals estimate that between 1 in 3 and 1 in 4 females are sexually abused in some way during childhood (Faller, 1993). Rates for males are believed to be approximately 1 in 10, with some suggesting that it may be as many as 1 in 6 (Faller, 1993).

It may be that male victims are less likely to be reported or identified compared with female victims. It is often suggested that sexual abuse of males is more underreported than that of females, due to societal tendencies not to view the behavior as abusive (e.g., sexual acts with an older female may be viewed by many, including the victim, as "experience" rather than abuse) (Faller, 1993). In addition, boys tend to be more reluctant to talk about their own victimization (Watkins \& Bentovim, 1992). This may be partially due to fears of homosexuality, or their socialization taught them that boys are supposed to be "tough" and the abuse was a failure on their part because they were unable to protect themselves.

Characteristics of the abuse experience also appear to be different between boys and girls. Boys tend to be victimized at younger ages especially when abused within the family (although reports vary on this account), are less likely to present as adolescents, are more likely to have been also physically abused, to have been sexually abused with force, or both, and tend to experience more severe and repeated abuse (Faller, 1989; Watkins \& Bentovim, 1992). As mentioned earlier, boys are more likely to be victims of extrafamilial abuse, and tend not to be solo victims (Faller, 1989). The NIS-3 also collected information about the perpetrators of maltreatment. The perpetrators of sexual abuse (according to the harm standard) were $29 \%$ birth parents, $25 \%$ other parents and parent substitutes (e.g., adoptive parents, stepparents, foster parents), and $46 \%$ others (e.g., other family members or other individuals) (NCCAN, 1996). Approximately $89 \%$ of perpetrators were male.

As many as $60 \%$ to $80 \%$ of adult offenders reported the onset of their sexual offenses as occurring in adolescence (Groth et al., 1982). Some studies have shown that about $20 \%$ of sexual assaults on children were committed by adolescents (Bagley \& ShewchukDann, 1991; Johnson, 1988), accounting for about $8 \%$ of male victims and $15 \%$ to $25 \%$ of female victims (Ryan, 1988).

Although not all victims of sexual abuse engage in sexually exploitive acts, a large proportion of adult and juvenile offenders report a history of victimization (Johnson, 1988; Watkins \& Bentovim, 1992; Worling, 1995). Adolescent offenders against children were significantly more likely to have been abused than those who assaulted peers or adults (20\% vs. 4\%; Worling, 1995). In addition, those offenders who had male victims had a higher chance of having a history of sexual abuse (Worling, 1995).

\section{Characteristics of the Victim}

\section{Developmental Context}

Adolescence is a time of individuation and experimentation, marked by the onset of puberty and the emergence of sexual activity. During adolescence, social interactions and relationships become increasingly complicated and adult-like. The peer group becomes 
larger and more complex, more time is spent with peers, and interactions with opposite-sex peers increase (Hansen et al., 1995). The desire for close friends increases, as adolescents turn to their peers for support formerly provided by the family, and the primarily samesex interests and playmates of childhood give way to opposite-sex interests and friendships (Hansen, Christopher, \& Nangle, 1992; Hansen et al., 1995). The more advanced cognitive and verbal abilities and the physical and emotional changes associated with puberty alter the adolescent's interactions with both same-sex and opposite-sex peers (Hansen et al., 1992). In addition, adolescents experience a variety of other changes within their family, peer group, school, and community (Peterson \& Hamburg, 1986).

Kirsh (1984) suggests that adolescence can be divided into three stages. Early adolescence characterizes males ages $12-14$ and females ages 11-13. These youth are primarily concerned with adjusting to the changes that their bodies are going through, new sexual feelings, and the fear that they will no longer be cared for as a child. Middle adolescence covers the period 14-16 for males and 13-15 for females. These adolescents tend to focus on becoming emotionally independent of their parents, the attractiveness of their bodies, and their sexual adequacy. Finally, late adolescence describes males and females ages 1619. These youth are preoccupied with concerns about their adequacies as men and women, their ability to form permanent relationships and to integrate sex and intimacy. As so many of these issues focus around sexuality, adolescents are particularly vulnerable to the impact of sexual abuse and the development of deviant behavior as a result of such abuse.

These developmental considerations are often overlooked in the understanding of the dynamics of abuse, specifically the vulnerability or risk of being abused and the impact that an occurrence of abuse will have on the individual. A recent conceptualization by Finkelhor (1995), developmental victimology, addresses these issues. Throughout childhood, individuals gain and lose characteristics that may make them more or less vulnerable for various types of victimization. For example, sexual maturation may make children, especially girls, at increased risk for sexual abuse (Finkelhor, 1995). As children grow older, they may be more able to run away, fight back, and utilize their social networks to gain support, and therefore are better able to protect themselves and prevent the recurrence of abuse. There also has been a tendency to believe that adolescents, due to their increased control over their environment, are largely responsible for their own victimization (Finkelhor, 1995). In fact, adolescents may give in to social pressures and engage in behaviors (e.g., using drugs and alcohol) that do not facilitate self-protection (Finkelhor, 1995).

The impact of abuse also appears to be related to developmental level. For example, there is some evidence suggesting that prepubescent abuse affects endocrine secretions, possibly resulting in the early onset of puberty (Finkelhor, 1995; Gil, 1996). Puberty brings about many uncomfortable feelings and issues related to body image, and an abusive experience during this time can have wide-ranging impact on an adolescent (Gil, 1996). Cognitively, an important dimension appears to be how children understand the concept of victimization and the perception of responsibility for the event (Finkelhor, 1995). Older children may be more at risk in this respect, as they are more able to understand the stigma associated with victimization. Also, the victim's sense of morality may be impacted, which would affect the way they view their own abuse and would have possible consequences on their future behaviors (Finkelhor, 1995). Their perception of power, right and wrong, and fairness may be shaped by abusive incidents, thus limiting their moral development and creating or encouraging a tendency to commit an abusive act. 


\section{Correlates and Possible Consequences}

There is no single profile of a sexually abused child, and the extent of the impact of abuse varies from individual to individual. Much of the research has been conducted with children. However, the dynamics and the consequences involved also apply to adolescents, especially since abuse often starts in childhood. Unfortunately, the research evidence is inconclusive as many practical and methodological issues make it difficult to identify the consequences of sexual abuse (Browne \& Finkelhor, 1986; Faller, 1993; Finkelhor, 1990; V. V. Wolfe \& Wolfe, 1988). The research is primarily correlational; therefore, causal relationships cannot be identified. The research evidence is further limited by the fact that it is unclear whether symptoms in abused children are directly a result of the abuse or more globally a by-product of family pathology and problems (Berliner, 1991; Hansen et al., 1998). As mentioned earlier, normal developmental changes also playa role. Research designs are extremely difficult to implement under these circumstances (e.g., heterogeneous population, developmental considerations, inability to randomly assign subjects or manipulate variables of interest, multiple possible variables to assess, multiple etiological and maintaining factors). The fact that abusive acts are illegal, private, and sometimes of relatively low frequency, also complicates research efforts because of the difficulty of assessment. The secrecy and shame associated with the abuse may cause many people never to disclose their experiences. Typically the most severe cases are the most likely to come to the authorities' attention, thus creating a biased sample. Despite the complexity of the issue, the available research in the field provides some insights regarding the varied possible consequences of child sexual abuse.

A number of studies and reviews have addressed the consequences of child sexual abuse (see reviews by Browne \& Finkelhor, 1986; Faller, 1993; Finkelhor, 1990; V. V. Wolfe \& Wolfe, 1988). The possible psychological consequences of sexual abuse are numerous and variable and no symptom or syndrome is found universally in all victims. It has been estimated that as many as $50 \%$ of abuse victims may be asymptomatic (Beutler et al., 1994). Many variables may affect whether and how abuse has an impact, including factors such as the gender of the victim and perpetrator, the type and severity of abuse, and the duration of and time since the abuse, and family reaction following disclosure (Browne \& Finkelhor, 1986; Faller, 1993). It may be that some victims are not strongly affected by abuse due to "protective" factors that prevent the negative effects of maltreatment (e.g., good family and social support, positive school experiences, therapy) (Falshaw, Browne, \& Hollin, 1996).

Research has found sexual abuse to be associated with a number of internalizing behaviors, including anxiety (e.g., McClellan, Adams, Douglas, McCurry, \& Storck, 1995), depression (e.g., Livingston, 1987; Wozencraft, Wagner, \& Pelligrin, 1991), problems with self-esteem (e.g., Tong, Oates, \& McDowell, 1987), suicidal ideation and attempts (e.g., Bayatpour, Wells, \& Holford, 1992; McClellan et al., 1995; Wozencraft et al., 1991), sleep disturbances (e.g., McClellan et al., 1995; Wells, McCann, Adams, Voris, \& Ensign, 1995), somatic complaints (e.g., Livingston, 1987), and fear of males (e.g., Wells et al., 1995). A number of studies have also noted the presence of externalizing behavior problems, including self-abusive behaviors (e.g., McClellan et al., 1995), delinquency (e.g., Einbender \& Friedrich, 1989), and cruelty (e.g., Einbender \& Friedrich, 1989; McClellan et 
al., 1995). In addition, problems with school performance (e.g., Einbender \& Friedrich, 1989; Wells et al., 1995) and concentration (e.g., Wells et al., 1995), as well as problems with relationships and social competence (e.g., Einbender \& Friedrich, 1989) have been identified as correlates of child sexual abuse.

Adolescent victims of sexual abuse may also exhibit substance abuse problems (Harrison, Hoffman, \& Edwall, 1989; McClellan et al., 1995; Singer, Song, \& Ochberg, 1994).). It has been suggested that the antecedents of alcoholism are similar to the consequences of sexual abuse, especially the factors of social isolation and emotional disturbances (B. A. Miller, Downs, Gondoli, \& Keil, 1987) Further, youth with a history of victimization saw greater perceived benefits (e.g., tension reduction, escape from family problems) in using substances, which led to increased levels of intoxication and drug use (Harrison et al., 1989; Singer et al., 1994).

Sexual behavior is another possible area of impact. Sexually abused children appear to know more about sex and are more interested and curious about sexual matters or genital regions (e.g., Friedrich \& Reams, 1987; Wells et al., 1995). Heightened sexual activity, such as compulsive masturbation, precocious sexual play, and overt sexual acting out toward adults and peers have been found among abused youth (e.g., McClellan et al., 1995). Another possible consequence of sexual abuse is self-consciousness about the youth's own body (Wells et al., 1995).

Reviews of teen pregnancies show that $50 \%-66 \%$ of adolescents who become mothers have a history of sexual abuse (Lanz, 1995; Rainey, Stevens-Simon, \& Kaplan, 1995). These rates greatly exceed the incidence of reported rape and child sexual abuse found in the general population (Lanz, 1995; Rainey et al., 1995). There is some evidence that sexually abused youth who become pregnant are likely to have multiple behavior problems, such as prepregnancy and perinatal substance abuse and suicide attempts (Bayatpour et al., 1992; Lanz, 1995). Pregnant teens with a history of sexual abuse also report higher levels of depression, anxiety, family dysfunction, and lower self-esteem than those without a history of victimization (Lanz, 1995; Rainey et al., 1995).

It commonly is believed that males tend to respond to abuse, as well as other stressors, with externalizing behaviors while females typically exhibit internalizing problems. Research to date with victims of sexual abuse does not support this general proposition (Watkins \& Bentovim, 1992). Initially, boys, like girls, may respond with sexualized behavior (Watkins \& Bentovim, 1992). Sexually abused boys are seen to have greater sexual identity confusion, lower self-esteem, and greater sexual dysfunction (Watkins \& Bentovim, 1992). Although sexually abused males report less psychological harm than sexually abused females, abused males exhibit more depression, anxiety, and interpersonal problems than nonabused males, and also have a greater preponderance of suicidal feelings and behaviors (Watkins \& Bentovim, 1992).

For males, an additional consideration may be their sexual self-concept (Richardson, Meredith, \& Abbot, 1993). Sexual self-concept is defined as the sex-typed role that a person identifies with and uses to describe oneself. This type of self-concept is typically categorized as masculine, feminine, androgynous, or undifferentiated (Bem, 1974). Sexually abused adolescent males are more likely than nonabused males to report undifferentiated sexual self-concepts, suggesting a poorly developed sense of sexual identity (Richardson et al., 1993). Correlates of this undifferentiated concept include poor adjustment, poor social relations, and lower self-esteem. 
Many scholars have tried to characterize the effects that abuse has on children and adolescents (e.g., Conte, 1985; Finkelhor, 1984; Friedrich, 1995). A conceptualization offered by Friedrich (1995), for example, categorizes the impact of trauma according to three dimensions: attachment, self-regulation, and self-perspective. Attachment problems refer to the detachment and interpersonal problems that are often present in abuse victims. This includes difficulties in trusting others and hypervigilance. Difficulties in selfregulation include behavioral problems such as impulsivity, aggression, and sexual acting out. Finally, self-perspective refers to the adolescent's integration of the abuse into his or her own sense of self, often leading to a negative self-image and identity problems.

\section{Conceptualizations About the Impact of Sex Abuse}

A variety of conceptualizations have also been offered to explain how sexual abuse has an impact. Understanding the possible mechanisms for the impact of abuse may be useful for assessment and treatment, as well as prevention of further problems, including offending behavior. Finkelhor (Browne \& Finkelhor, 1985, 1986; Finkelhor \& Browne, 1985) proposed one of the best-known conceptualizations of the psychological impact of sexual abuse. In this model, sexual abuse is analyzed in terms of four trauma causing factors or "traumagenic dynamics": traumatic sexualization, betrayal, powerlessness, and stigmatization. Traumatic sexualization is the process by which the child' s sexuality is affected in away that is developmentally inappropriate and interpersonally dysfunctional. Betrayal refers to the dynamic wherein a person upon whom the child once depended has caused harm. The child' s trust and vulnerability are manipulated, expectations that others will provide protection are violated, and there is a lack of support and protection from caregivers. Powerlessness or disempowerment refers to the dynamic in which the victim's will, desires, and sense of efficacy are compromised. The dynamic includes the invasion of bodily territory, the use of force or trickery to involve the child, the child's inability to believe the abuse occurred, and feelings of vulnerability, fear, and the inability to protect oneself. The final traumagenic dynamic is stigmatization, which refers to the negative feelings of guilt, shame, lowered self-esteem, and a sense of differentness from others. This traumagenic conceptualization of the impact of sexual abuse is one of the most parsimonious and comprehensive models to date; yet, the model is subject to criticism. For example, these dynamics have not been demonstrated to be consequences of abuse, the extent or presence of these dynamics varies considerably, and not all victims experience all dynamics (Conte, 1990).

Conte $(1985,1990)$ suggested that sexual abuse has first- and second-order sources of trauma or impact. First-order factors are the direct result of sexual abuse, such as the sexual behavior itself and actions by perpetrators to gain sexual access to the child and maintain silence (e.g., threat, force, bribes). Second-order factors result from processing first-order events. For example, threats or force may create fear, which may result in the development of abuse-specific fears (e.g., fear of the perpetrator or the location where the abuse occurred) or more general fear (e.g., men).

Newberger and DeVos (1988) offered a transactional model that identifies the process of interaction among three dimensions in the impact and recovery from sexual abuse: social cognition, environmental sensitivity, and emotional-behavioral functioning. The social cognition domain consists of the youth's cognitive appraisal of the event. 
Beliefs about control and personal efficacy potentially influence the outcome of abuse. For example, the belief that the victimization is one's own fault may contribute to poorer outcomes. The second domain, environmental sensitivity, suggests that the environmental context influences the youth's psychological processes and functioning. Interactions with parents, relatives, friends, adults, community institutions (i.e., school, sports teams), legal and law enforcement institutions, and therapists may lessen or exacerbate the impact of abuse. The final domain consists of the youth's emotional (e.g., distress, anxiety, depression) and behavioral functioning (e.g., aggression, somatization, sexualized behavior, achievement). The domains are believed to be active and mutually influence one another, so that alterations in one domain change functioning in other domains (Newberger \& DeVos, 1988).

\section{Risk of Becoming an Offender}

Victims of sexual abuse are at increased risk of becoming offenders (e.g., Bagley \& Shewchuk-Dann, 1991; Rasmussen, Burton, \& Christopherson, 1992). In fact, many of the correlates of sexual abuse also are correlates of offending; such correlates are marital tension in the family, maternal psychopathology, paternal psychopathology (particularly alcoholism), and harsh discipline (Bagley \& Shewchuk-Dann, 1991). Other factors associated with sexual offending include depression, anxiety, social inadequacy and selfconcept problems, lack of intimacy, and lack of accountability for one's actions (Bagley \& Shewchuk-Dann, 1991; Rasmussen et al., 1992). Additional common precursors to offending behavior include hyperactivity, impulsiveness, and learning disorders (Bagley \& Shewchuk-Dann, 1991; Watkins \& Bentovim, 1992). Since the majority of known sex offenders are male, special consideration needs to be paid to the circumstances surrounding male victims (Faller, 1989).

Based on the available research, Watkins and Bentovim (1992) have proposed a model of perpetrator risk following sexual abuse. They proposed that being male is a risk, and that being molested by a male or having had multiple perpetrators places one at greater risk. If the perpetrator is a close relative, risk is also increased. In addition, more severe abuse, repeated over time increases the chances that the victim will later offend. When the victim is young (e.g., under 8 years of age), the chances are increased that he will eventually offend. Other risk factors include the diagnoses of Conduct Disorder, Posttraumatic Stress Disorder, Attention Deficit Disorder, and Learning Disabilities. In addition, children exhibiting anxious sexualization (e.g., a dysphoric aspect associated with the sexualized behavior), externalized coping strategies, sexual identity confusion, or who identify with the aggressor are at greater risk. Those who are isolated and do not get treatment for their own abuse also may be at increased risk to offend.

Finkelhor (1984) has developed the Four Preconditions Model of Sexual Abuse; a potential offender must meet these preconditions before committing an assault. First, the potential offender must be motivated to abuse. This suggests that the offender feels that relating to the child will fulfill an emotional need, and that other sources of sexual release are not perceived to be available, or are not as satisfying. This motivation may also be connected to a need for power and control, or it may be a reenactment of the potential offender's own personal trauma. This "cycle of abuse, " or reenactment, may be an at- 
tempt to achieve mastery over the conflicts of past history, and may condition the potential offender to become sexually aroused by assaultive fantasies (Worling, 1995). Second, Finkelhor (1984) discussed the importance of overcoming internal inhibitors. The use of alcohol or the presence of psychosis or an impulse disorder may enable the, potential offender to overcome these inhibitions. Family dynamics that support incestuous relationships also may contribute, and may help to explain the intergenerational transmission of abuse. The third precondition involves predispositions to overcoming external inhibitors. These consist of having an absent, ill or emotionally distant mother in the child's family, a patriarchical father, or social isolation of the family. Poor supervision of the child and the potential offender helps to remove some of these external constraints. Finally, the potential offender must overcome the child's resistance. In many cases, this means that the child trusts the offender due to their prior relationship, or the child is insecure, deprived, or both, or merely lacks knowledge of sexual abuse.

Lane (1991) has proposed a Sex Abuse Cycle, which details the thoughts and characteristics of potential offenders that may contribute to their behavioral choices. Lane focused on the power-based thinking and cognitive errors in which these individuals engage. Specifically, these adolescents feel that they are unable to control the environment (perhaps due to their own victimization), and think that gaining power and domination resolves problems. This identification with their own offender is not uncommon, and often can lead to the reduction of anxiety surrounding their own abuse (Watkins \& Bentovim, 1992). These youth also tend to exhibit some conduct disordered beliefs, such as that having an urge or impulse, acting on it, and "getting away" with it is a sign of competence, and that it is acceptable to manipulate others (Lane, 1991). Acts of delinquency might actually give these youth a sense of control, and they might learn that intimidation and coercion are reliable ways of meeting their goals. Lane (1991) further described these potential offenders as having no empathy. They typically have unrealistic expectations and a sense of ownership and entitlement. They refuse to accept responsibility for their acts, and often do not think ahead to the consequences of their actions. Ryan (1991a) suggested that the anxiety that occurs after the first offense is commonly overcome by feelings of entitlement.

\section{Family Patterns}

The response to adolescence often depends on the type of family structure that is present and the family response can affect the likelihood of maltreatment and its impact (Garbarino, 1989; Lourie, 1977; Ryan, 1991b). In authoritarian families, there usually is not much freedom afforded to the adolescent, which may lead the adolescent to either rebel or become overly dependent (Garbarino, 1989). If the parental discipline has been unduly harsh, there is a chance that the youth will become overtly aggressive and hostile (Garbarino, 1989). Parents in these authoritarian families typically use considerable denial and minimizing, and their marriages are characterized by a lack of intimacy and availability (Pelcovitz, Kaplan, Samit, Krieger, \& Cornelius, 1984). The parents are then united when dealing with the acting-out behaviors of their child. Permissive or overindulgent parents may create resentment in adolescents if they are viewed as overprotective, overly indulgent, or enmeshed (Garbarino, 1989). The parents often have a hard time dealing with the potential threat of separation, and due to the overindulgent patterns throughout the youth's childhood, the adolescent may not be prepared for the responsibilities of 
growing up (Pelcovitz et al., 1984). These adolescents may feel "smothered, " especially in intimate and sexual relationships (Garbarino, 1989). Poor supervision in these families may also be a risk related to victimization as well as offending behavior.

Lourie (1977) hypothesized that for some adolescents, abuse can be a result of the failure of the family to readjust to the structural changes that are created by the youth's movement toward autonomy. In this stage the youth and the family need to accept that the child is moving out of the role of a "controlled and dependent" family member and is separating from the family (Lourie, 1977). The family and adolescent also must adapt to physical changes and sexual maturity.

As some adolescent victims become sexual offenders, it is important to look at family patterns of offenders. Family characteristics that are common among juvenile sex offenders include distant or unstable relationships and unhealthy sexual activities of the adults (e.g., sexually deviant acts or open behavior in front of the child) (Becker, Harris, $\&$ Sales, 1993). Coercive patterns may exist and these manipulative behaviors may be reinforced in the family environment teaching the youth that coercion is a means of controlling others. These families also tend to be emotionally impoverished, utilizing inappropriate affect and often "scapegoating" the offender with the negative feelings of the family (Ryan, 1991b).

Ryan (1989) went farther to explain three types of family systems associated with juvenile sex offending. The "exploitive family" is characterized by a lack of unconditional positive regard and the child is typically used by the parent or parents to meet their own needs. These parents tend to have very high expectations for their children. The "rigid/ enmeshed family" typically has many secrets and is isolated from the external community. Family members are dependent on each other and are afraid of abandonment. "Chaotic/ disengaged family" members cannot provide support for one another. They tend to interact in immature ways and concentrate on their own individual crises.

Clinical lore has supported the belief that the intergenerational transmission of maltreatment is a common occurrence. Given the relative lack of empirical evidence to support this link, however, the best that can be said is that a history of abuse is a risk factor to offending behavior (Falshaw et al., 1996; Kaufman \& Zigler, 1989; Widom, 1989). Research provides some evidence for the intergenerational transmission of sexual abuse; however, these studies generally suffer from methodological flaws, such as small, nonrepresentative samples and retrospective designs (Kaufman \& Zigler, 1989; Watkins \& Bentovim, 1992; Widom, 1989). Specific estimates regarding rates of intergenerational transmission of sexual abuse are described later.

Special considerations may be in place for the intergenerational transmission of abuse with adolescent parents. As noted earlier, sexual abuse increases the likelihood of adolescent pregnancy (Lanz, 1995; Rainey et al., 1995). In addition, these mothers may be more likely to have children who are abused. A prospective study by Boyer and Fine (1992) indicated that adolescent mothers who were sexually abused were three times more likely to have children who were maltreated than nonabused adolescent mothers. Another recent investigation showed that a history of chronic sexual abuse increased the chances that an adolescent mother would be involved with Child Protective Services (Spieker, Bensley, McMahon, Fung, \& Ossiander, 1996). The majority of cases were reported for neglect not sexual abuse, however. The mothers who reported histories of abuse also reported less supportive relationships with their families and 
more prepregnancy drug use (Spieker et al., 1996), suggesting that assessment of additional contextual variables (e.g., family support, substance abuse) is also important in examining possible intergenerational links.

Several theories have attempted to address the mechanisms of transmission. For example, a sociological view suggests that when parents and children share an environment and culture with norms that support abusive behavior, the continuance of abuse is likely (Kaufman \& Zigler, 1989). Social learning theory suggests that by witnessing and experiencing the behavior, children are experiencing conditioned patterns of arousal, learning that it is appropriate, and are forming rules and cognitive distortions around these beliefs (Kaufman \& Zigler, 1989; Widom, 1989). Psychodynamic approaches suggest that the victim is attempting to overcome the trauma of abuse by identifying with the aggressor (Bagley, Wood, \& Young, 1994). Similarly, attachment theory states that internalized representations of past relationships serve as templates that dictate future relationships, and abusive patterns are integrated into these models (Kaufman \& Zigler, 1989).

\section{Assessment and Diagnosis}

There are two core parts to assessment in cases of adolescent abuse: (1) defining the symptoms that are consequences of the abuse that the adolescent experienced, and (2) identifying the risk factors that may lead the youth to later offend. Of course, there are some unique problems associated with getting information from adolescents, and these are compounded for sexually abused adolescents who for a variety of reasons are often untrusting of others (Azima \& Dies, 1989). In cases where perpetration is an issue, the youth may be even less willing to comply, especially given that they are likely to have committed offenses that have not yet been discovered. Adolescents may be unwilling to fill out the "school-like forms" that characterize many assessment measures (Azima \& Dies, 1989). These youth also may be afraid of exposing secrets and admitting feelings related to inferiority, sexual inadequacy, and their drug and alcohol use (Azima \& Dies, 1989) and will minimize these behaviors. It is important, therefore, to be very straightforward and honest with the adolescent, explaining the constraints of confidentiality, and stressing that honesty in the assessment process will help ensure better treatment. It is helpful to start with some of the more general, less threatening topics in the assessment process, such as measures of global adjustment, mood, or personality, before addressing some of the more intimate topics, such as substance use, sexual history, victimization, and perpetration.

Building rapport is very important, as the clinical interview will often provide some of the most critical information. Given the wide range of possible consequences of sexual abuse, it is necessary to gather information about the youth's functioning across domains (e.g., school, home, peers), as well as a thorough description of family dynamics and their current complaints, symptoms, and level of functioning. Conducting collateral interviews with parents and other significant people (e.g., teachers) is also recommended. Special attention should be paid to those issues that are identified with the risk to sexually offend. These include social isolation, impulsivity, conduct disordered behaviors, and limited cognitive abilities (Watkins \& Bentovim, 1992). Questions about any prior involvement with the legal system are also important (Perry \& Orchard, 1992), and any deviant activities of the peer group should also be explored (Watkins \& Bentovim, 1992). 
Family characteristics, such as parental behavior and attitudes about sex, as well as parent-child and marital relationships, should be discussed (Watkins \& Bentovim, 1992).

Given the range of possible psychological consequences associated with sexual abuse, assessments should address a variety of internalizing and externalizing symptoms. Measures such as the Child Behavior Checklist, youth and Parent Report (Achenbach, 1991) for younger adolescents and the Symptom Checklist-90-R (Derogatis, 1994) for older adolescents are good measures of global functioning and symptomatology. More specific measures of anxiety and depression may also be helpful. Such measures as the Children's Depression Inventory (Kovacs, 1992), the Reynolds Adolescent Depression Scale (W. M. Reynolds \& Coats, 1985), and the Revised Children's Manifest Anxiety Scale (C. R. Reynolds \& Richmond, 1978) all contain norms for adolescents. Because higher rates of suicidal ideation and behavior are found among this population of adolescents, special attention should be paid to this issue, and the youth should be asked about suicidal thoughts directly, even if they do not endorse the specific items on the measures. The Inventory of Suicidal Orientation-30 (ISO-30; King \& Kowalchuk, 1994) is a useful tool for measuring the magnitude of suicidal thoughts and orientation in adolescents.

Personality measures can also provide useful information about current psychopathology and patterns of functioning that may be maladaptive. The Minnesota Multiphasic Personality Inventory-Adolescent (MMPI-A; Butcher et al., 1992) is a widely used measure of adolescent pathology and functioning, including dimensions such as treatment compliance, attitudes towards therapeutic change, drug and alcohol use, and adolescent-specific areas (e.g., family relationships, school behavior, peer-group influences). This measure also contains validity scales that help indicate whether the respondent is being open or defensive in his or her report. Another measure is the Millon Adolescent Clinical Interview (MACI; Millon, Millon, \& Davis, 1993). This self-report inventory was designed specifically to assess adolescent personality characteristics (e.g., submissive, dramatizing, unruly, oppositional) and adolescent concerns (e.g., sexual discomfort, peer insecurity, identity diffusion). It also measures clinical syndromes such as eating dysfunctions, delinquent predisposition, impulsive propensity, and others.

As mentioned earlier, youth who have a history of sexual abuse are well represented among those with substance abuse problems. In addition to the subscales of the MMPI$\mathrm{A}$ and the MACI that address these concerns and the propensity to develop addiction problems, direct measurement and questioning should be used surrounding this issue. The Substance Abuse Subtle Screening Inventory (SASSI), Adolescent Version (G. A. Miller, 1985) differentiates substance abusers from social users, regardless of deliberate deception attempts on the part of the respondent.

In order to assess the risk of an adolescent's turning to sexually aggressive behavior, the clinician has to consider several dimensions. The clinical interview should address accountability, cognitive distortions, self-esteem, and conduct disordered behaviors, since these are all precursors or correlates of offending behavior. Issues of power, entitlement, and poor empathy skills also are important in determining an individual's risk to offend. Even though sexually assaultive behavior may not be present, some of the attitudes and thinking errors that are expressed may be associated with offending behaviors. The assessment should also address attitudes toward sex and dating. Many rape prevention programs work under the assumption that the development of empathy will increase prosocial behavior and decrease aggression (Schewe \& O’Donohue, 1993). Measures such 
as the Attitudes Towards Rape scale (Feild, 1978) and the Rape Empathy Scale (Deitz, Blackwell, Daley, \& Bentley, 1982) can give some indication of an adolescent's beliefs. In addition, knowledge about their fantasies and their initiation into sexual experiences should be obtained. It also might be helpful to ask about family attitudes toward sex and how the youth learned about sex.

If it is known that the youth has sexually offended, additional information should be obtained. Details about the assaults, including the sexual acts performed, the duration and frequency of the offending behavior, the use of force, and the age of the victim or victims are all important. Questions pertaining to victim empathy (e.g., "How did she respond?" "What do you think she was feeling?") should be asked to assess the offender's level of empathy and the extent of distorted thinking that may be present. Other information about the selection and "grooming" of victims, fantasies, and feelings of the offender before and after the assault are important as well, to identify problems and guide treatment.

\section{Course and Prognosis}

As noted earlier, research has identified a variety of possible short-term consequences of sexual abuse (Browne \& Finkelhor, 1986; Faller, 1993; Finkelhor, 1990; V. V. Wolfe $\&$ Wolfe, 1988). Somewhat less is known about the long term consequences of sexual abuse. The research on long-term effects is also complicated by even more obstacles (e.g., the need for longitudinal design) that make it more difficult to identify the correlates and possible consequences of sexual abuse. Commonly identified long-term effects include anxiety, depression, self-destructive behavior, poor self-esteem, feelings of isolation, difficulty trusting others, substance abuse, patterns of revictimization, sexual dysfunction, and sexual deviance (Browne \& Finkelhor, 1986; Falshaw et al., 1996; V. V. Wolfe \& Wolfe, 1988).

It was also noted earlier that one of the most critical possible consequences of sexual abuse is sexual offending (Bagley \& Shewchuk-Dann, 1991; Lane, 1991; Rasmussen et al., 1992). Like all of the research on sexual abuse, however, research in the area of intergenerational effects of sexual abuse on sexual offending is also difficult to conduct and inherently contains some serious methodological problems. For example, longitudinal designs are most informative but few researchers have the resources available for that type of undertaking. In addition, legal records as sources of data on sexual offending do not reflect the cases in which a sexual offense or other deviant act was perpetrated but not reported. The sample sizes are often small and good comparison groups are hard to find.

Although such limitations prevent drawing firm conclusions from the literature, there is some useful information available. For example, research with small samples of male adolescents has found rates of sexual offending subsequent to sexual abuse in 13\% (Friedrich, Beilke; \& Urquiza, 1988) to 50\% (Sansonnett-Hayden, Hayley, Marriage, \& Fine, 1987). In a review of the pooled prevalence rate across available research, Watkins and Bentovim (1992) found that $22 \%$ of the sexually abused male youth in the various samples exhibited offending behavior. Looking prospectively or retrospectively may affect the results of the studies. Watkins and Bentovim (1992) referred to a study that claimed that a retrospective analysis indicated a $90 \%$ rate of intergenerational transmis- 
sion of physical abuse, while a prospective analysis indicated a rate of only $18 \%$. In a review of related studies involving adolescent male offenders, Worling (1995) found that $31 \%$ (range $=19 \%-55 \%$ ) reported some form of sexual abuse, which is triple the rate of men in the general population who have experienced sexual abuse.

As we know very little about sexual offending by adolescent females, an unanswered question is why so few females, as compared with males, become abusers as a consequence of their own abuse, especially since higher numbers of female victimization are reported. It has been suggested that women are socialized to be more sexually submissive than men, as well as more nurturing; this socialization pattern decreases the chances that they will act out by creating more internal inhibitions that they must overcome before offending (Watkins \& Bentovim, 1992). In addition, boys may have more childhood sexual experiences than girls, and may actually become physiologically aroused and sexually conditioned more quickly than girls (Watkins \& Bentovim, 1992).

Some authors have suggested that a specific form of abuse is most likely to lead to the same type of violence (e.g., sexual abuse leads to sexual violence, physical abuse leads to physical violence) (e.g., Bagley et al.; Falshaw et al., 1996; Rasmussen et al., 1992; Ryan, 1989). In contrast, some authors have suggested that specific maltreatment type does not lead to the same type of offending and that any type of victimization may lead to any category of crime (Benoit \& Kennedy, 1992; Widom \& Ames, 1994). There is, however, no clear or inevitable progression from victim to offender (Falshaw et al., 1996). The majority of maltreated children do not become aggressive or delinquent (Falshaw et al., 1996; Widom, 1989).

\section{Clinical Management}

Clinical assessment and treatment with adolescents are commonly believed to pose special clinical challenges. In the case of adolescent victims, clinical management is further challenged by the complex picture of sexual abuse. For example, the adolescent can be removed from the home for several reasons. The family may have difficulties that interfere with their ability to take care of the teen. The teen may be in immediate danger from another family member, or the youth's own behavior may be endangering another family member. In addition, there is a need to determine whether the youth can be treated on an outpatient basis. Psychosis, poor impulse control, severe conduct problems, prior treatment failures, and, in the cases of offenders, the amount and severity of the assaults may suggest a more restrictive setting (DiGiorgio-Miller, 1994). Given the complexities associated with treatment of adolescent sexual abuse, systematic consideration of treatment adherence, generalization, and social validity are needed to facilitate effective assessment, treatment, and research.

The full involvement of the adolescent and family in treatment is essential for treatment success. Three types of treatment adherence are needed: attending sessions regularly, participating within sessions, and completing out-of-session assignments or tasks (e.g., using skills learned) (Lundquist \& Hansen, 1998). A variety of possible contextual factors may increase or decrease the likelihood of treatment adherence, including stress factors or setting events, such as conflict within the family, social isolation, low parental education, low socioeconomic status, and so forth. A variety of specific problems can arise, 
such as transportation problems, illness, forgetting, and parent or family concerns about obtaining mental health services. In addition, the adolescents often do not come to treatment of their own accord. Their parents or other authority figures usually have identified a problem and have required the adolescent to enter treatment. In some cases, the court might be involved and therapy may be mandated.

Given the growing importance of autonomy during adolescence, and the lack of control and power that often goes along with being a victim of abuse, a certain amount of resistance should be expected with this population. Resistance can be seen at micro or macro levels (Sutton \& Dixon, 1986). At the micro level, clients can challenge, disagree, and otherwise negate the therapist's suggestions within the session. At the macro level, resistance is evidenced by clients not completing homework assignments, missing appointments, or dropping out of the session. Newman (1994) suggested that the therapist consider the following questions when dealing with client resistance: (a) "What is the function of the client's resistant behaviors?" (b) "How does the client's current resistance fit into his or her developmental/historical pattern of resistance?" (c) "What might be some of the client's idiosyncratic beliefs that are feeding into his or her resistance?" (d) "What might the client fear will happen if he or she complies?" (e) "What skills does the client lack that might make it practically difficult or impossible at this point for him or her to actively collaborate with treatment?" and (f) "What factors in the client's natural environment may be punishing the client's attempts to change?" (pp, 51-55).

In addition to completion of a specific functional analysis of each client's adherence, the clinician should note the general antecedent and consequent strategies that may facilitate treatment adherence, Antecedent strategies include addressing client cognitions that precede or accompany negative reactions to therapy, having an empathic or skilled therapist, involving the client in goal and procedure selection, providing additional stimuli such as reminder cards, beginning with small homework requests and gradually increasing assignments, ensuring that assignments contain specific details relevant to the desired behavior, and providing specific training for the tasks to be implemented (Lundquist \& Hansen, 1998). Consequent strategies that may promote adherence include use of praise or tangible reward, and feedback and shaping procedures. In addition, approaches that use both antecedent and consequent strategies are valuable; these approaches include working with referral sources (e.g., schools, courts, Child Protective Services), advocating for the client, using cognitive rehearsal strategies (e.g., self-management, self-reinforcement), and using contingency management and behavioral contracting, Proactive problem solving for potential obstacles to adherence may increase the likelihood of adherence.

As noted earlier, there are some unique problems associated with getting information from adolescents, as they are often untrusting of others and reluctant to comply and participate (Azima \& Dies, 1989). In addition, sexual abuse is typically surrounded by secrecy and shame, and is difficult to talk about. The client must be informed that some things cannot be kept confidential (e.g., disclosures of assaults). If the assessment is court-ordered, the information will go to the courts. If new victims or perpetrators are discussed, these must also be reported through the appropriate channels. It is helpful to start with some of the more general, less threatening topics. Building rapport is very important, and could be especially challenging in cases where assessment or treatment is court-ordered. Many times adolescent victims of abuse prefer a female therapist (DiGiorgio-Miller, 1994). 
Three types of generalization treatment effects are usually needed: (a) stimulus generalization, including demonstration of behavior gains in other settings or with new people, or both; (b) response generalization, including changes in behaviors that have not been specific targets of intervention; and (c) temporal generalization or maintenance of treatment effects over time. To achieve generalization it is important to program for it actively (Stokes \& Osnes, 1989). A wide variety of strategies are possible, including contacting and recruiting natural consequences (e.g., appropriate peer and family reinforcers), training diversely (e.g., using sufficient stimulus and response exemplars), incorporating functional mediators (e.g., common salient physical and social stimuli, self-mediated physical and verbal stimuli), and targeting contextual factors (e.g., social isolation, family stressors) that interfere with skill acquisition or limit use of newly acquired skills (Lundquist \& Hansen, 1998; Stokes \& Osnes, 1989). Teaching general strategies for problem solving and coping can enhance generalization and maintenance (Stokes \& Osnes, 1989). Use of relevant and effective treatment strategies is, of course, the most critical part of achieving lasting, generalized impact.

Group treatment is believed to be useful for enhancing the generalization of treatment (Damon \& Waterman, 1986; Hansen et al., 1998). Group treatment provides I increased exposure to the problems, strategies, and solutions of others; additional opportunity for modeling of appropriate behaviors and responses; opportunities to rehearse skills with more individuals; and extensive opportunity for feedback, support, and reinforcement from group members and the therapist.

The involvement of the parents in treatment is probably the most important strategy for enhancing maintenance and generalization. Parents are the persons who are responsible for the health, well-being, and safety of the child, and are generally with the child more than any other adult. They are going to be most able to identify and address problems that may arise, both during and long after treatment. The family, as well as the victim, might have faulty attributions about the abuse and the adolescent that need to be addressed (Berliner, 1991). For example, it can be very helpful to deal with the parents' expectations and anxiety about the impact of the abuse on their child (Hansen et al., 1998).

Because of the often intergenerational nature of sex abuse, it is frequently found that the mothers have been sexually abused and they need to work through their own trauma again so that they can be helpful to their children (Damon \& Waterman, 1986). There is often an impaired relationship between victims and their mothers, especially in incest cases, and it is often unclear whether symptoms in these youth are directly a result of the abuse or more globally a by-product of family pathology (Berliner, 1991). Involvement of parents in treatment facilitates the identification and remediation of these issues; this should lead to more lasting and generalized effects.

Ensuring that the goals, procedures, and outcomes of therapy are socially or functionally valid is also valuable (Kazdin, 1977). Therapists need to consider whether the treatment goals are what the adolescent, family, and society want and whether achieving the goals would actually improve the adjustment and effectiveness of the individual. Therapists also need to consider whether the adolescent victim and family members consider the assessment and treatment procedures acceptable. Finally, therapists need to consider whether clients and relevant others (e.g., family, teachers, judges, other legal authorities) are satisfied with all of the effects of treatment (i.e., whether behavior changes of individual, social, or applied importance have been achieved). 
Treatment adherence, generalization, and social validity have generally been discussed as separate concepts, but it is important to note that there is significant overlap among the concepts (Lundquist \& Hansen, 1998). For example, the more socially valid the goals and the procedures, the more likely the client is to adhere to treatment; the more likely the client is to participate in treatment, the more likely the effects will generalize and maintain; the more the effects generalize and maintain, the more socially valid and functional the effects.

\section{Treatment}

Given the well-documented problems of sexual abuse, the lack of empirically validated treatments is surprising. Although we have learned much over the years, treatments have typically lacked a theoretical basis and evaluation has been minimal and poorly conducted (Conte, 1990; Hansen et al., 1998; O'Donohue \& Elliot, 1992). The treatment literatures relevant for sexually abused adolescents have, for the most part, been developed and evaluated separately; some research addresses the needs of victims (e.g., internalizing and externalizing behaviors, sexual education) and some addresses prevention of sexual offending.

Many of the treatments for adolescents with a history of sexual abuse are described in the literature that focuses on females (e.g., Blick \& Porter, 1982; Furniss, Bingley-Miller, \& Van Elburg, 1988). The goals of therapy generally deal with helping the adolescents communicate about the abuse experiences, enhance self-esteem, learn and discuss issues surrounding normal sexuality, talk about appropriate family roles and boundaries, overcome isolation, and develop healthy peer relationships (Blick \& Porter, 1982; Furniss et al., 1988). Special considerations have been suggested for boys. Specifically, boys need help opening up, especially in asking for help (Watkins \& Bentovim, 1992). They also need to discuss their fears and issues surrounding homosexuality and their attitudes toward women, especially family members (Watkins \& Bentovim, 1992).

As noted previously, group treatment has advantages for facilitating generalization. Azima and Dies (1989) suggested that a group modality with adolescents has advantages because the format reflects the shift in importance that adolescents typically place on their peers and away from their parents. Group therapy allows them to see themselves in relation to others within a safe environment. It also lets them work through some of their feelings of rebelliousness and hostility toward authority. Mainly, group therapy allows the youth to see that they are not alone, that their problems are not unique, and that there are other people who understand what they are going through, thus reducing their feelings of isolation. The emotional support provided by the group has immediate effects that may ultimately facilitate continued involvement in therapy. Of course, not every youth is a candidate for group therapy, and many adolescents may also require individual and family therapy in addition to the group.

The importance of parental involvement in treatment for enhancing generalization and maintenance has also been discussed. Research indicates that parental support after disclosure may be a key factor in reducing the impact of sexual abuse, including maintaining school performance and peer relations and protection against serious mental health symptoms (Hansen et al., 1998). Poor family support, as evidenced by conflict and 
poor cohesion, is related to increased likelihood of internalizing and externalizing problems (Friedrich et al., 1988). Support may protect the victims by assisting them in processing what happened to them in a less negative way and ensuring that they obtain needed services (Wozencraft et al., 1991).

Although parental support is important for reducing the effects of sexual abuse, it is important to remember that the family may be experiencing its own emotional distress in reaction to the youth's victimization. When a youth is victimized, it affects not only the abuse victim but the entire family system, and family members may need support for the feelings and stressors that they are experiencing. Davies (1995) examined parental distress and ability to cope following disclosure of extrafamilial sexual abuse. Most parents felt that they needed assistance dealing with the abuse, especially during the early postdisclosure stage. Problems experienced by parents following disclosure included increased strain for both parent-child and spousal relationships, depression, posttraumatic stress, and unresolved anger. Families may not only need assistance in dealing with the aftermath of child sexual abuse, but parents may also need assistance in adjusting to their own preexisting mental health issues. For example, maternal history of sexual abuse or maternal psychiatric symptoms may interact with the youth's response to the sexual abuse (Friedrich \& Reams, 1987). Family variables may interact with abuse related variables in a manner that exacerbates or modifies the possible maladjustment noted in sexually abused youth, and thus family therapy may be needed.

A limited number of treatment programs are available for sexual abuse victims and the research evidence supporting them is limited (Hansen et al., 1998; O'Donohue \& E1liot, 1992). The majority of available research and treatment programs have addressed younger child victims (e.g., Berliner, 1991; Damon \& Waterman, 1986), though clinicians have begun to address the treatment needs of adolescent victims I (e.g., Blythe et al.; 1990; Gil, 1996; Prendergast, 1994). Unfortunately, even when research or clinical experience suggests that a procedure is effective, other sites may not be able to replicate the process because of the lack of standardized treatment protocols (Hansen et al., 1998).

A newly developed treatment protocol for child and adolescent sexual abuse victims and their nonoffending parents, referred to as Project SAFE (or Sexual Abuse Family Education), was developed from a systematic analysis of the literature (Hecht, Futa, \& Hansen, 1995) and based on a three-factor model of the target areas impacted by sexual abuse: the individual or "self" (e.g., self-esteem, guilt, fears); relationships (peer, family); and sex (sexual knowledge, sexual abuse-specific knowledge) (Hansen et al., 1998). This treatment protocol utilizes a parallel group format, with separate groups running simultaneously for the youth and their nonoffending parents. Treatment procedures include education, skill building, problem solving, and support. Treatment modules cover topics such as understanding and recognizing feelings, sharing what happened, addressing family and social support issues, relaxation and coping with feelings, basic education about sex and sexual abuse, and empowerment and self-assertion. Although such standardized treatment programs are valuable and provide guidance for clinicians and researchers alike, more evaluation is needed to firmly establish their impact (Hansen et al., 1998; O'Donohue \& Elliot, 1992). The treatment literature in this area is plagued by the methodological problems commonly found in sexual abuse research (e.g., small and heterogenous samples, inability to randomly assign subjects, multiple possible variables to assess and treat) as well as all of the difficulties 
found in the conduct of treatment research (e.g., difficulty of demonstration of experimental control, lack of adequate comparison groups).

Addressing the current psychological needs of the victims of abuse can also impact the conditions that are associated with the likelihood of future offending. Victims and offenders share many similar characteristics, such as low self-esteem, peer problems, social isolation, feelings of powerlessness, and behavior problems (Watkins \& Bentovim, 1992). Certain principles are suggested in the treatment of victims that also pertain to the prevention of future offending. Control is an important factor in abuse, and victims often perceive a lack of control that generalizes from the abuse experience to other aspects of their life. Returning control to the victim is a powerful intervention strategy, and can be accomplished through assisting the victim to make appropriate decisions (Prendergast, 1994). Ambivalent feelings toward the perpetrator also need to be addressed. In many cases, such ambivalence might result in identification with the abuser, leading the victim to then become a perpetrator (Pescosolido, 1993). It is important to teach these adolescents the distinction between caring about a person and liking their behaviors (Prendergast, 1994). Dealing with identity confusion is another critical component of treatment (Pescosolido, 1993; Prendergast, 1994). As discussed earlier, traumatic events can have a considerable impact on the development of a sense of self. This disruption may lead the victim to identify with the abuser, or may create a negative self-image that affects many other aspects of the adolescent's life. Thus, reforming self-image can be an important part of therapy.

Schacht, Kerlinsky, and Carlson (1990) discussed a coed group run with inpatient psychiatric patients who were both victims and offenders. In addition to histories of abuse, these youth also exhibited behaviors such as poor impulse control, poor problem solving, limited insight, and problems with regulation of emotions. The goals of this therapy included ending abusive relationships and developing victim empathy, increased selfrespect, willingness to take responsibility for own behaviors, increased impulse control, improved problem-solving skills, decreased anger and depression, improved trust and peer relations, and a positive, open attitude toward sexuality. The therapists reported several special issues that needed to be addressed during treatment. They found that some of the boys felt that they had to be the "abuser" within the group in order to deal with their discomfort. This led to a broader discussion of abuse, including emotional abuse, intimidation, humiliation, and invasion of personal space.

In order to interrupt the cycle of intergenerational abuse, efforts at primary and secondary prevention with high-risk groups are necessary. Primary prevention of perpetration involves social, cultural, and familial change in order to help change the early socialization experiences of the children in the family and community (Ryan, 1991c). Secondary prevention efforts involve intervention with children who have been abused and neglected, physically or sexually or both, institutionalized, or undersocialized (Ryan, 1991c). The approach with adolescents in these preventive efforts should focus on the fostering of empathy in order to prevent exploitive behavior (Hagan, King, \& Patros, 1994; Ryan, 1991c). Issues such as helplessness, powerlessness, and perceived lack of control have been identified as triggers that start the assault cycle (Ryan, 1991c). Specifically, youth who are trying to regain a sense of control and well-being often harbor negative and unrealistic expectations about interpersonal relationships, and think that an external source of gratification may compensate for negative experiences. 
D. A. Wolfe and his colleagues (1996) have developed an impressive program targeting adolescents at-risk to become offenders. Adolescents with a history of victimization are involved in groups designed to help them understand the abuse of power and control on their own relationships and how this may impact their future behaviors. Specifically, goals for males include being able to identify and express their feelings assertively, recognizing and respecting the personal rights of others, especially in dating situations, and learning to take responsibility for their behavior. For females, the goals are understanding their own personal rights, learning how to take care of their own personal safety, and developing assertive communication skills. This program teaches adolescents the skills to help them build healthy relationships and to recognize and respond to abuse in their own relationships as well as those of peers. It focuses on power dynamics, interpersonal violence, and ways of breaking out of the cycle. Specifically, positive and assertive communication and problem-solving skills are emphasized. In addition to instruction about the skills, the youth are asked to actively use these skills during role-plays. Gender stereotypes are addressed and corrected as well. This treatment protocol has been empirically validated, and is one of the few available programs aimed specifically at the prevention of offending by targeting potential offenders.

Other treatment approaches focus specifically on the problems of an identified adolescent perpetrator, which is tertiary prevention. These programs must address issues such as accountability, the abuse cycle, arousal and fantasy, power and control, the consequences of sexual abuse and victim empathy, cognitive distortions (e.g., denial, minimization), positive and healthy sexuality, impulse control, and skills deficits (NAPN, 1993). Treatment of adolescent sex offenders also involves relapse prevention, or teaching the youth to recognize the precursors to offending behaviors and teaching the skills to interrupt the assault cycle. A variety of literature (e.g., Becker et al., 1993; Perry \& Orchard, 1992; Ryan, 1989), including several workbooks and treatment materials (e.g., Kahn, 1990; Steen, 1993), is available that addresses these issues. Detailed elaboration of these approaches is beyond the scope of this chapter but more information can be found in Becker and colleagues (1993) on adolescent sexual offenders.

\section{Conclusion}

Adolescence is a transitional developmental period that is characterized by physical, cognitive, social, and emotional changes. Many adolescents are further stressed by being a victim of sexual abuse. Sexual abuse is a widespread problem with serious and varied consequences for adolescent victims. Adolescents, for a variety of reasons (e.g., puberty, peer influences), are likely to begin engaging in sexual acts and victims of sexual abuse are particularly at risk to develop sexualized behaviors. Research evidence suggests that adolescent victims need special attention to help prevent the intergenerational transmission of abuse. Despite the increased attention to the problem of adolescent sexual abuse in recent decades, there is still much to learn about providing effective treatment. Future research must further develop and evaluate effective intervention strategies for adolescent sexual abuse victims, including treatment for the varied consequences of abuse and prevention of offending behavior. 


\section{References}

Achenbach, T. M. (1991). Manual for the Child Behavior Checklist/4-18 and 1991 Profile. Burlington: University of Vermont Press.

Azima, F. J. C., \& Dies, K. R (1989). Clinical research in adolescent group psychotherapy: Status, guidelines, and directions. In F. J. C. Azima \& L. H. Richmond (Eds.), Adolescent group psychotherapy (pp. 193-223). Madison, CT: International Universities Press.

Bagley, C., \& Shewchuk-Dann, D. (1991). Characteristics of 60 children and adolescents who have a history of sexual assault against others: Evidence from a controlled study. Journal of Child and Youth Care [Special issue], 43-52.

Bagley, C., Wood, M., \& Young, L. (1994). Victim to abuser: Mental health and behavioral sequelae of child sexual abuse in a community survey of young adult males. Child Abuse \& Neglect, 18, 683-697.

Bayatpour, M., Wells, R. D., \& Holford, S. (1992). Physical and sexual abuse as predictors of substance use and suicide among pregnant teenagers. Journal of Adolescent Health, 13, 128-132.

Becker, J. V., Harris, C. D., \& Sales, B. D. (1993). Juveniles who commit sexual offenses: A critical review of research. In G. C. N. Hall, R. Hirschman, J. R. Grahm, \& M. S. Zaragoza (Eds.), Sexual aggression: Issues in etiology, assessment, and treatment (pp. 215-228). Washington, DC: Taylor \& Francis.

Bern, S. L. (1974). The measurement of psychological androgeny. Journal of Consulting and Clinical Psychology, 42, 155-162.

Benoit, J. L., \& Kennedy, W. A. (1993). The abuse history of male adolescent sex offenders. Journal of Interpersonal Violence, 7, 543-548.

Berliner, L. (1991). Therapy with victimized children and their families. New Directions for Mental Health Services, $51,29-46$.

Beutler, L. E., Williams, R. E., \& Zetzer, H. A. (1994) Efficacy of treatment for victims of child sexual abuse. The Future of Children, 4, 156-175.

Blick, L. C., \& Porter, F. S. (1982). Group therapy with female adolescent incest victims. In S. M. Sgroi (Ed.), Handbook of clinical intervention in child sexual abuse (pp. 147-176). Lexington, MA: Lexington Books.

Blythe, B., Hodges, V., \& Guterman, N. (1990). Intervention for maltreated adolescents. In M. Rothery \& G. Cameron (Eds.), Child maltreatment: Expanding our concept if helping (pp. 33-47). Hillsdale, NJ : Erlbaum.

Boyer, D., \& Fine, D. (1992). Sexual abuse as a factor in adolescent pregnancy and child maltreatment. Family Planning Perspectives, 24, 4-12.

Browne, A., \& Finkelhor, D. (1.985). The traumatic impact of child sexual abuse: A conceptualization. American Journal of Orthopsychiatry, 55, 530-541.

Browne, A., \& Finkelhor, D. (1986). Impact of child sexual abuse: A review of the research. Psychological Bulletin, 99, 66-77.

Butcher, J. N., Williams, C. L., Graham, J. R., Archer, R. P., Tellegen, A., Ben-Porath, Y. S., \& Kaemmer, B. (1992). MMPI-A: Minnesota Multiphasic Personality Inventory-Adolescent. Minneapolis: University of Minnesota Press.

Conte, J. R. (1985). The effects of sexual abuse on children. A critique and suggestions for future research. Victimology, 10, 110-130.

Conte, J. R. (1990). Victims of child sexual abuse. In R. T. Ammerman \& M. Hersen (Eds.), Treatment of family violence: A sourcebook (pp. 50-76). New York: Wiley.

Damon, L., \& Waterman, J. (1986). Parallel group treatment of children and their mothers. In K. MacFarlane \& J. Waterman (Eds.), Sexual abuse of young children (pp. 244-298). New York: Guilford.

Davies, M. G. (1995). Parental distress and ability to cope following disclosure of extrafamilial sexual abuse. Child Abuse \& Neglect, 19, 399-408.

Deitz, S., Blackwell, K., Daley, P., \& Bentley, B. (1982). Measurement of empathy toward rape victims and rapists. Journal of Personality and Social Psychology, 43, 372-383.

Derogatis, L. R. (1994). SCL-90-R: Administration, scoring, and procedures manual (3rd ed.). Towson, MD: Clinical Psychometric Research.

DiGiorgio-Miller, J. (1994). Clinical techniques in the treatment of juvenile sex offenders. Journal of Offender Rehabilitation, 21, 117-126.

Einbender, A. J., \& Friedrich, W. N. (1989). Psychological functioning and behavior of sexually abused girls. Journal of Consulting and Clinical Psychology, 57, 155-157.

Faller, K. C. (1989). Characteristics of a clinical sample of sexually abused children: How boy and girl victims differ. Child Abuse \& Neglect, 13, 281-291. 
Faller, K. C. (1993). Child sexual abuse: Intervention and treatment issues. Washington, DC: U.S. Department of Health and Human Services.

Falshaw, L., Browne, K. D., \& Hollin, C. R. (1996). Victim to offender: A review. Aggression and Violent Behavior, 4, 389-404.

Feild, H. S. (1978). Attitudes towards rape: A comparative analysis of police, rapists, crisis counselors and citizens. Journal of Personality and Social Psychology, 36, 156-179.

Finkelhor, D. (1984). Child sexual abuse: New theories and research. New York: Free Press.

Finkelhor, D. (1990). Early and long-term effects of child sexual abuse: An update. Professional Psychology: Research and Practice, 21, 325-330.

Finkelhor, D. (1995). The victimization of children: A developmental perspective. American Journal of Orthopsychiatry, 65, 177-193.

Finkelhor, D., \& Browne, A. (1985). The traumatic impact of sexual abuse: An update. Professional Psychology: Research and Practice, 21, 325-330.

Friedrich, W. N. (1995). Managing disorders of self-regulation in sexually abused boys. In M. Hunter (Ed.), Child survivors and perpetrators of sexual abuse: Treatment innovations (pp. 3-23). Newbury Park, CA: Sage.

Friedrich, W. N., \& Reams, R. A. (1987). Course of psychological symptoms in sexually abused young children. Psychotherapy, 24, 160-170.

Friedrich, W. N., Beilke, R. L., \& Urquiza, A. I. (1988). Behaviour problems in young sexually abused boys. Journal of Interpersonal Violence, 3, 21-28.

Furniss, T. , Bingley-Miller, L. , \& Van Elburg, A. (1988). Goal-oriented group treatment for sexually abused adolescent girls. British Journal of Psychiatry, 152, 97-106.

Garbarino, I. (1989). Troubled youth, troubled families: the dynamics of adolescent maltreatment. In D. Cicchetti \& V. Carlson (Eds.), Child maltreatment: Theory and research on the causes and consequences of child abuse and neglect (pp. 685-706). New York: Cambridge University Press.

Gil, E. (1996). Treating abused adolescents. New York: Guilford.

Gonsiorek, J. C. (1994a). Diagnosis and treatment of young adult and adolescent male victims: An individual psychotherapy model. In J. C. Gonsiorek, W. H. Bera, \& D. LeTourneau (Eds.), Male sexual abuse: A trilogy of intervention strategies (pp. 56-110). Thousand Oaks, CA: Sage.

Gonsiorek, J. C. (1994b). Historical and background perspectives on adolescent and male sexual abuse. In J. C. Gonsiorek, W. H. Bera, \& D. LeTourneau (Eds.), Male sexual abuse: A trilogy of intervention strategies (pp. 3-20). Thousand Oaks, CA: Sage.

Groth, A. N., Longo, R. E., \& McFadin, J. B. (1982). Undetected recidivism among rapists and child molesters. Crime \& Delinquency, 28, 450-458.

Hagan, M. P., King, R. P., \& Patros, R. L. (1994). Recidivism among adolescent perpetrators of sexual assault against children. Journal of Offender Rehabilitation, 21, 127-137.

Hansen, D. J., Christopher, J. S., \& Nangle, D. W. (1992). Adolescent heterosocial interactions and dating. In V. B. Van Hasselt \& M. Hersen (Eds.), Handbook of social development: A lifespan perspective (pp. 371394). New York: Plenum.

Hansen, D. J., Giacoletti, A. M., \& Nangle, D. W. (1995). Social interactions and adjustment. In V. B. Van Hasselt \& M. Hersen (Eds.), Handbook of adolescent psychopathology: A guide to diagnosis and treatment (pp. 102-129). New York: Macmillan.

Hansen, D. J., Hecht, D. B., \& Futa, K. T. (1998). In V. B. Van Hasselt \& M. Hersen (Eds.), Handbook of psychological treatment protocols for children and adolescents (pp. 153-178). New York: Erlbaum.

Harrison, P. A., Hoffman, N. G., \& Edwall, G. E. (1989). Sexual abuse correlates: Similarities between male and female adolescents in chemical dependency treatment. Journal of Adolescent Research, 4, 382-399.

Hecht, D. B., Futa, K. T., \& Hansen, D. J. (1995, November). A qualitative analysis of group therapy for sexually abused children and adolescents: How prior treatments can guide future interventions. Paper presented at the Convention of the Association for the Advancement of Behavior Therapy, Washington, DC.

Johnson, T. C. (1988). Child perpetrators-Children who molest other children: Preliminary findings. Child Abuse \& Neglect, 12, 219-229.

Kahn, T. J. (1990). Pathways: A guided workbook for youth beginning treatment. Brandon, VT: Safer Society Press.

Kaufman, J., \& Zigler, E. (1989). The intergenerational transmission of child abuse. In D. Cicchetti \& V. Carlson (Eds.), Child maltreatment: Theory and research on the causes and consequences of child abuse and neglect (pp. 129-150). New York: Cambridge University Press.

Kazdin, A. E. (1977). Assessing the clinical or applied importance of behavior change through social validation. Behavior Modification, 1, 427-452. 
Kempe, C. H., Silverman, F., Steele, B., Droegenmueller, W., \& Silver, H. (1962). The battered child syndrome. Journal of the American Medical Association, 181, 17-24.

King, J. D., \& Kowalchuk, B. (1994). ISO-30-Adolescent: Inventory of Suicide Orientation-30. Minneapolis, MN: National Computer Systems.

Kirsh, S. (1984). Adolescent problems and related practices. In F. Maidman (Ed.), Child welfare: A source book of knowledge and practice (pp. 289-323). New York: Child Welfare League of America.

Kovacs, M. (1992). Children's Depression Inventory. North Tonowonda, NY: Multi-Health Systems.

Lane, S. (1991). The sexual abuse cycle. In G. D. Ryan \& S. L. Lane (Eds.), Juvenile sexual offending: Causes, consequences, and correction (pp. 103-141). Lexington, MA: Lexington Books.

Lanz, J. B. (1995). Psychological, behavioral, and social characteristics associated with early forced sexual intercourse among pregnant adolescents. Journal of Interpersonal Violence, 10, 188-200.

Livingston, R. (1987). Sexually and physically abused children. Journal of the American Academy of Child and Adolescent Psychiatry, 26, 413-415.

Lourie, I. S. (1977). The phenomenon of the abused adolescent: A clinical study. Victimology: An International Journal, 2, 268-276.

Lundquist, L. M., \& Hansen, D. J. (1998). Enhancing treatment adherence, social validity, and generalization of parent-training interventions with physically abusive and neglectful families. In J. R. Lutzker (Ed.), Handbook of child abuse research and treatment (pp. 449-471). New York: Pergamon.

McClellan, J., Adams, J., Douglas, D., McCurry, C., \& Storck, M. (1995). Clinical characteristics related to severity of sexual abuse: A study of seriously mentally ill youth. Child Abuse \& Neglect, 19, 1245-1254.

Miller, B. A., Downs, W. R., Gondoli, D. M., \& Keil, A. (1987). The role of childhood sexual abuse in the development of alcoholism in women. Violence and Victims, 2(3), 157-172.

Miller, G. A. (1985). The Substance Abuse Subtle Screening Inventory (SASSI) manual. Spencer, IN: Spencer Evening World.

Millon, T., Millon, C., \& Davis, R. (1993). MACI manual: Millon Adolescent Clinical Inventory. Minneapolis. MN: National Computer Systems.

National Adolescent Perpetrator Network. (1993). The revised report from the national task force on juvenile sexual offending. Juvenile and Family Court Journal, 44(4), 5-121.

National Center on Child Abuse and Neglect. (1996). Third national incidence study of child abuse and neglect. Washington, DC: U.S. Department of Health and Human Services.

Newberger, C. M., \& DeVos, E. (1988). Abuse and victimization: A life-span developmental perspective. American Journal of Orthopsychiatry, 58, 505-511.

Newman, C. (1994). Understanding client resistance: Methods for enhancing motivation to change. Cognitive and Behavioral Practice, 1, 47-69.

O'Donohue, W. T., \& Elliot, A. N. (1992). Treatment of the sexually abused child: A review. Journal of Clinical Child Psychology, 21, 218-228.

Pelcovitz, D., Kaplan, S., Samit, C., Krieger, R., \& Cornelius, D. (1984). Adolescent abuse: Family structure and implications for treatment. Journal of the American Academy of Child Psychiatry, 23, 85-90.

Perry, G. P., \& Orchard, J. (1992). Assessment and treatment of adolescent sex offenders. Sarasota, FL: Professional Resource Press.

Pescosolido, F. J. (1993). Clinical considerations related to victimization dynamics and post-traumatic stress in the group treatment of sexually abused boys. Journal of Child and Adolescent Group Therapy, 3, 49-73.

Petersen, A. C., \& Hamburg, B. A. (1986). Adolescence: A developmental approach to problems and psychopathology. Behavior Therapy, 17, 480-499.

Prendergast, W. E. (1994). Initial steps in treating child and adolescent survivors of sexual abuse. Journal of Offender Rehabilitation, 21, 89-115.

Rainey, D. Y., Stevens-Simon, C., \& Kaplan, D. W. (1995). Are adolescents who report prior sexual abuse at higher risk for pregnancy. Child Abuse \& Neglect, 10, 1283-1288.

Rasmussen, L. A., Burton, J. E., \& Christopherson, B. J. (1992). Precursors to offending and the trauma outcome process in sexually reactive children. Journal of Child Sexual Abuse, 1, 33-48.

Reynolds, C. R., \& Richmond, B. 0. (1978). What I think and feel: A revised measure of children's manifest anxiety. Journal of Abnormal Child Psychology, 6, 271-280.

Reynolds, W. M., \& Coats, K. I. (1985). A comparison of cognitive-behavioral therapy and relaxation training for the treatment of depression in adolescents. Journal of Consulting and Clinical Psychology, 54, 653660.

Richardson, M. F., Meredith, W., \& Abbot, D. A. (1993). Sex-typed role in male adolescent sexual abuse survivors. Journal of Family Violence, 8, 89-100. 
Rogers, C. M., \& Terry, T. (1984). Clinical intervention with boy victims of sexual abuse. In I. R. Stuart \& J. G. Greer (Eds.), Victims of sexual aggression: Treatment of children, women, and men (pp. 91-104). New York: Van Nostrand Reinhold.

Ryan, G. (1988, April). The juvenile sexual offender: A question of diagnosis. Paper presented at the National Symposium on Child Victimization, Anaheim, CA.

Ryan, G. (1989). Victim to victimizer: Re-thinking victim treatment. Journal of Interpersonal Violence, 4, 325341.

Ryan, G. (1991a). Consequences for the juvenile sex offender. In G. D. Ryan \& S. L. Lane (Eds.), Juvenile sexual offending: Causes, consequences, and correction (pp. 175-181). Lexington, MA: Lexington Books.

Ryan, G. (1991b). The juvenile sex offender's family. In G. D. Ryan \& S. L. Lane (Eds.), Juvenile sexual offending: Causes, consequences, and correction (pp. 143-160). Lexington, MA: Lexington Books.

Ryan, G. (1991c). Perpetration prevention: Primary and secondary. In G. D. Ryan \& S. L. Lane (Eds.), Juvenile sexual offending: Causes, consequences, and correction (pp. 393-408). Lexington, MA: Lexington Books.

Sansonnett-Hayden, H., Hayley, G., Marriage, C., \& Fine, S. (1987). Sexual abuse and psychopathology in hospitalized adolescents. Journal of the American Academy of Child and Adolescent Psychiatry, 26, 753757.

Schacht, A. J., Kerlinsky, D., \& Carlson, C. (1990). Group therapy with sexually abused boys: Leadership, projective identification, and countertransference issues. International Journal of Group Psychotherapy, 40, 401-417.

Schewe, P. A., \& O'Donohue, W. (1993). Sexual abuse prevention with high-risk males: The roles of victim empathy and rape myths. Violence and Victims, 8, 339-351.

Showers, J., Farber, E. D., Joseph, J. A., Oshino, L., \& Johnson, C. F. (1983). The sexual victimization of boys: A three year study. Health Values: Achieving High Level Wellness, 7, 15-18.

Singer, M. I., Song, L., \& Ochberg, B. (1994). Sexual victimization and substance abuse in psychiatrically hospitalized adolescents. Social Work Research, 18, 97-103.

Spieker, S. J., Bensley, L., McMahon, R. J., Fung, H., \& Ossiander, E. (1996). Sexual abuse as a factor in child maltreatment by adolescent mothers of preschool aged children. Development and Psychopathology, $8,497-509$.

Steen, C. (1993). The relapse prevention workbook for youth in treatment. Brandon, VT: Safer Society Press.

Stokes, T. F., \& Osnes, P. G. (1989). An operant pursuit of generalization. Behavior Therapy, 20, 337-355.

Sutton, C. S., \& Dixon, D. (1986). Resistance in parent training: A study of social influence. Journal of Social and Clinical Psychology, 4, 133-144.

Tong, L., Oates, K., \& McDowell, M. (1987). Personality development following sexual abuse. Child Abuse \& Neglect, 11, 371-383.

Watkins, B. , \& Bentovim, A. (1992). The sexual abuse of male children and adolescents: A review of current research. Journal of Child Psychology and Psychiatry, 33, 197-248.

Wells, R. D., McCann, J ., Adams, J ., Voris, J ., \& Ensign, J. (1995). Emotional, behavioral, and physical symptoms reported by parents of sexually abused, nonabused, and allegedly abused prepubescent females. Child Abuse \& Neglect, 19, 155-163.

Widom, C. S. (1989). Does violence beget violence? A critical examination of the literature. Psychological Bulletin, 106, 3-28.

Widom, C. S., \& Ames, M. A. (1994). Criminal consequences of childhood sexual victimization. Child Abuse \& Neglect, 18, 308-318.

Williamson, J. M., Borduin, C. M., \& Howe, B. A. (1991). The ecology of adolescent maltreatment: A multilevel examination of adolescent physical abuse, sexual abuse, and neglect. Journal of Consulting and Clinical Psychology, 59, 449-457.

Wolfe, D. A., Wekerle, C., Gough, R., Reitzel-Jaffe, D., Grasley, C., Pittman, A., Lefebvre, L., \& Stumpf, J. (1996). The youth relationships manual: A group approach with adolescents for the prevention of woman abuse and the promotion of healthy relationships. Thousand Oaks, CA: Sage.

Wolfe, V. V., \& Wolfe, D. A. (1988). The sexually abused child. In E. J. Mash \& L. G. Terdal (Eds.), Behavioral assessment of childhood disorders (2nd ed., pp. 670-714). New York: Guilford.

Worling, J. R. (1995). Sexual abuse history of adolescent male sex offenders: Differences on the basis of the age and gender of their victims. Journal of Abnormal Psychology, 104, 610-613.

Wozencraft, T., Wagner, W., \& Pelligrin, A. (1991). Depression and suicidal ideation in sexually abused children. Child Abuse \& Neglect, 15, 505-511. 